\title{
Food in synchrony with melatonin and corticosterone relieves constant light disturbed metabolism
}

\author{
Adrián Báez-Ruiz1,2, Natalí N Guerrero-Vargas1,3, Fernando Cázarez-Márquez', \\ Elizabeth Sabath', María del Carmen Basualdo', Roberto Salgado-Delgado², \\ Carolina Escobar ${ }^{3}$ and Ruud M Buijs ${ }^{1}$
}

1Department of Physiology and Cellular Biology, Biomedical Research Institute, UNAM, DF, México ${ }^{2}$ Department of Cellular Physiology, Faculty of Science, UASLP, San Luis Potosí, México

${ }^{3}$ Department of Anatomy, Faculty of Medicine, UNAM, DF, México

\author{
Correspondence \\ should be addressed \\ to R M Buijs \\ Email \\ ruudbuijs@gmail.com
}

\begin{abstract}
Circadian disruption is associated with metabolic disturbances such as hepatic steatosis (HS), obesity and type 2 diabetes. We hypothesized that HS, resulting from constant light (LL) exposure is due to an inconsistency between signals related to food intake and endocrine-driven suprachiasmatic nucleus (SCN) outputs. Indeed, exposing rats to LL induced locomotor, food intake and hormone arrhythmicity together with the development of HS. We investigated whether providing temporal signals such as 12-h food availability or driving a corticosterone plus melatonin rhythm could restore rhythmicity and prevent the metabolic disturbances under LL conditions in male rats. Discrete metabolic improvements under these separate treatments stimulated us to investigate whether the combination of hormone treatment together with mealtime restriction (12-h food during four weeks) could prevent the metabolic alterations. LL exposed arrhythmic rats, received daily administration of corticosterone $(2.5 \mu \mathrm{g} / \mathrm{kg})$ and melatonin $(2.5 \mathrm{mg} / \mathrm{kg})$ in synchrony or out of synchrony with their $12-\mathrm{h}$ meal. HS and other metabolic alterations were importantly ameliorated in LL-exposed rats receiving hormonal treatment in synchrony with 12-h restricted mealtime, while treatment out of phase with meal time did not. Interestingly, liver bile acids, a major indication for HS, were only normalized when animals received hormones in synchrony with food indicating that disrupted bile acid metabolism might be an important mechanism for the HS induction under LL conditions. We conclude that food-elicited signals, as well as hormonal signals, are necessary for liver synchronization and that HS arises when there is conflict between food intake and the normal pattern of melatonin and corticosterone.
\end{abstract}

Key Words

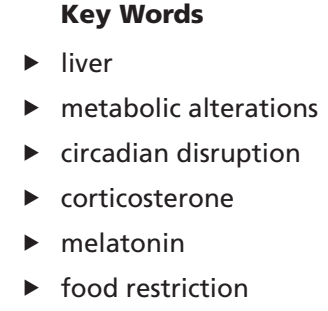

Journal of Endocrinology (2017) 235, 167-178

\section{Introduction}

The suprachiasmatic nucleus (SCN) coordinates circadian timing of metabolic processes and energy homeostasis using two main pathways: the endocrine and the autonomic nervous system (Kalsbeek et al. 2006). In this respect, there are numerous data highlighting corticosterone and melatonin as important circadian regulated hormones maintaining metabolic homeostasis and energy balance (Bedrosian et al. 2016). The daily peak of glucocorticoids is associated with the onset of the activity period, thus preparing the organism by inducing catabolic reactions

Published by Bioscientifica Ltd 
of energy stores (Dallman et al. 2004). Corticosterone is in addition involved in the regulation of metabolic processes including gluconeogenesis and lipolysis as well as maintaining a high-amplitude expression rhythmic in the circadian clock Per genes (Rose \& Herzig 2013, Polidarová et al. 2016). The melatonin peak occurs only during the dark period (its synthesis is prevented by light exposure) and influences energy balance, insulin production, secretion and action and participates in synchronizing insulin-sensitive metabolic processes (Cipolla-Neto et al. 2014, Owino et al. 2016). For example, melatonin treatment diminishes body weight gain and hepatic lipid accumulation in rodent models of diet-induced obesity (Prunet-Marcassus et al. 2003, Hatzis et al. 2013). Exogenous melatonin also protects from deleterious effects of constant light exposure (LL): melatonin given to animals subjected to LL, enhances glucose utilization, improves lipid metabolism and ameliorates oxidative stress related to exacerbated bile acid accumulation (Mustonen et al. 2002, Cruz et al. 2003). In contrast, glucocorticoids have negative side effects on metabolism stimulating hepatic and adipose lipogenic activity and VLDL secretion and decreasing insulin sensitivity (Ashley et al. 2011, Chimin et al. 2014). However, these effects are obtained by the administration of very high doses of glucocorticoids, used to treat inflammatory diseases. Interestingly, there is also evidence that in addition to the dose and treatment duration; when corticosterone is given at the time of day when the normal peak occurs less severe side effects are noted (Wu et al. 2016).

Several studies indicate that disturbing the circadian system leads to metabolic dysregulation. Nevertheless, up till now, there are no clear experimental data to what extent the disturbance of the rhythmicity of hormones in association with the disturbance in the rhythm of food intake is important for metabolic dysregulation. In this sense, alteration of daily secretion of glucocorticoids and melatonin caused by circadian disruption (shift-work, extended illumination exposure or daytime feeding) are proposed to be related to metabolic dysregulation (Bedrosian et al. 2016). Thus, rhythmic secretion of these hormones is suggested to be necessary to maintain the temporal patterns of peripheral metabolism (Prasai et al. 2014). It is suggested for example that the presence of glucocorticoid-responsive elements found in the clock gene Per1-2 promoters, could explain how corticosterone can contribute to the process of resetting the circadian rhythmicity of peripheral genes (Balsalobre et al. 2000). Furthermore, glucocorticoids also prevent a rapid uncoupling of peripheral oscillators when restricted feeding occurs in the rest period, enhancing the circadian time signals transmitted by the SCN and delaying the daytime meal effect (Le Minh et al. 2001). In addition, melatonin influences the expression of Rev-erb $\alpha$, a nuclear receptor implicated in the circadian regulation of SREBP signaling (an important lipid metabolism regulator) and bile acid homeostasis (Le Martelot et al. 2009, Polidarová et al. 2016).

Also, the fed-fasting cycle driven by the SCN acts as entraining signals for cellular processes in the liver, adipose tissue and muscle (Dibner et al. 2010, Buijs et al. 2013). In agreement with this, hepatic triglyceride (TG) content is temporally regulated by the SCN and feeding time (Adamovich et al. 2014). Exposing rodents to LL leads to circadian disruption, which is associated with metabolic alterations including hepatic steatosis (HS), dyslipidemia, disruption of bile acid homeostasis, insulin insensitivity and increased adipose mass (Ma et al. 2009, Shimba et al. 2011, Coomans et al. 2013, Aoki et al. 2014). Interestingly, similar health problems are observed in persons exposed to conditions of circadian misalignment, such as those with night-eating syndrome and shiftwork schedules (Goel et al. 2009, Gooley \& Chua 2014). Therefore, understanding physiological processes leading to HS and its prevention is of great importance. Hence, we hypothesize that LL in rodents, causes a loss of synchrony between the endocrine time signals driven by the SCN and food-related signals, causing a metabolic misbalance in the liver that leads to HS.

\section{Material and methods}

\section{Animals}

Male Wistar rats 200-220g (six weeks of age) were individually housed in acrylic cages inside soundproof lockers with controlled temperature of $22^{\circ} \mathrm{C}$, in a $12: 12$ light:darkness cycle (lights on at 8:00h, geographical time, defined as zeitgeber time or ZT0) and free access to water and to a standard diet food (Rodent Laboratory Chow 5001) until otherwise stated. Animals were randomly assigned to each of the following experimental group by a simple randomization method as previously described (Suresh 2011). Importantly, cage cleaning and food/water changes were realized weekly and randomly in order to avoid external time cues for the rats subjected to LL condition. The current study was approved by the Ethics Committee of the Universidad Nacional Autónoma 
de México, in agreement with the Federal Regulations of Animal Care and Use (NOM-062-ZOO-1999).

\section{Experimental design}

Experiment 1 aimed to confirm that LL is a circadian disrupting procedure leading to HS and other metabolic alterations. Rats under ad libitum conditions were randomly assigned to two groups: (A) maintained in a 12:12 light:darkness (LD) cycle (LD-AL, $n=7$ ) and (B) exposed to chronic constant light (LL) for six weeks (LL-AL, $n=7$ ).

Experiment 2. In order to test if in LL-arrhythmic animals (after three weeks of LL exposure), induced rhythmic hormonal cycles could prevent HS, a group of ad libitum fed LL rats were randomly divided in two groups: (A) daily administration of vehicle at 8:00 h ( LL + Veh, $n=8$ ) and (B) receiving daily hormonal (corticosterone $2.5 \mu \mathrm{g} / \mathrm{Kg}$ and melatonin $2.5 \mathrm{mg} / \mathrm{Kg}$ ) treatment given at 8:00h $(\mathrm{LL}+\mathrm{H}, n=6)$. Both groups received the daily treatment for four weeks.

Experiment 3 explored whether restricting food for $12 \mathrm{~h}$ in LL animals for a period of four weeks could prevent or ameliorate metabolic disturbances caused by circadian disruption. Two randomized groups of rats were assigned to the following conditions: (A) rats under ad libitum maintained in a 12:12 light:darkness (LD) cycle (LD-AL, $n=6$ ) and (B) animals made arrhythmic by chronic LL exposure (three weeks) with 12-h food access (LL-RF, $n=6$ ). All groups were followed and monitored during four weeks.

Experiment 4 tested in LL-arrhythmic rats whether daily food for $12 \mathrm{~h}$, combined with scheduled hormonal treatment could prevent HS compared to animals that received 12-h food only. Arrhythmic LL rats (exposed to LL for three weeks) were subdivided into three groups: (1) restricted food access (from 20:00 to 8:00 h; LL-RF, $n=6$ ), (2) restricted food access (from 8:00 to 20:00 h) scheduled in phase with hormonal treatment, hormones given at 8:00h (LL $+\mathrm{H}-\mathrm{RFi}, n=9$ ) or (3) restricted food access (from 20:00 to 8:00 h) out of phase with hormonal treatment at 8:00h (LL+H-RFo, $n=9)$.

\section{Tissue collection}

Animals were killed using an overdose of pentobarbital at the end of the food intake period according to each food schedule condition: at 8:00h for LD-AL, LL-AL,
$\mathrm{LL}+\mathrm{Veh}, \mathrm{LL}+\mathrm{H}, \mathrm{LL}-\mathrm{RF}$ and $\mathrm{LL}+\mathrm{H}-\mathrm{RF}$ groups and at 20:00 h for $\mathrm{LL}+\mathrm{H}-\mathrm{RFi}$ groups respectively. Whole liver and epididymal (eWAT), retroperitoneal (rWAT) and subcutaneous (inguinal) fat pads (sWAT) were collected, weighed and stored at $-80^{\circ} \mathrm{C}$. One week before killing, all groups were 16-h food deprived such that the onset of food deprivation was $4 \mathrm{~h}$ before the time the animals normally received food. Blood was collected under fasting conditions for hormones and metabolites determination at 9:00h (ZT1), 14h (ZT6) and 20h (ZT12) from tail puncture. Serum obtained was stored at $-80^{\circ} \mathrm{C}$.

\section{Behavioral monitoring}

Rats were housed in individual cages inside soundproof lockers. Animal displacements in the cage were monitored daily with electric pressure sensors placed under the cages. Behavioral events were recorded with a digitized system and every minute stored for further analysis with the program for PC SPAD9 designed for this system (Omnialva SA de CV). Double plotted actograms were constructed representing the number of activity counts every $15 \mathrm{~min}$. A $\chi^{2}$ periodogram was obtained from the last 10 days of monitoring.

\section{Body weight and food consumption}

Body weight was determined at the beginning and at the end of each protocol. Body mass gain was registered every week such, to have similar feeding conditions for all groups: (a) at 8:00 h (ZTO) for LD-AL, $\mathrm{LL}+\mathrm{Veh}, \mathrm{LL}+\mathrm{H}$, $\mathrm{LL}-\mathrm{RF}$ and LL+H-RFo groups and at 20:00h (ZT12) for $\mathrm{LL}+\mathrm{H}-\mathrm{RFi}$ groups respectively. These parameters were included in an equation illustrating the food efficiency for each experimental group as reported previously (Moura et al. 2012).

\section{Glucose tolerance test (GTT)}

GTT was determined as previously described (SalgadoDelgado et al. 2013). Briefly, control and experimental groups were fasted overnight just before the normal feeding time (or the equivalent time in the LL groups, $16 \mathrm{~h}$ fasting). Blood sampling (basal) was obtained (from tail puncture) at ZTO $(8: 00 \mathrm{~h})$ in the case of LD-AL, LL+Veh, $\mathrm{LL}+\mathrm{H}$, LL-RF and LL+H-RFo and at ZT12 (20:00h) $\mathrm{LL}+\mathrm{H}$-RFi groups respectively, such that all animals were analyzed at the same circadian time. Blood samples were collected before and after $1 \mathrm{~g}$ i.p. glucose administration http://joe.endocrinology-journals.org DOI: $10.1530 / J O E-17-0370$
๑) 2017 Society for Endocrinology Printed in Great Britain
Published by Bioscientifica Ltd. 
$(15,30,60$ and $120 \mathrm{~min}$ respectively). Glucose level was determined with a blood glucose monitor (Glucose meter, Chip, Abbott).

\section{Hormonal treatment}

Arrhythmic rats after 3 weeks in LL received melatonin and corticosterone once every $24 \mathrm{~h}$ to mimic their respective humoral circadian rhythms for an additional 4 weeks. Slow-release melatonin (Chronocaps; Productos Medix S.A. de C.V., México City, México) pill fragments equivalent to a concentration of $2.5 \mathrm{mg} / \mathrm{kg}$ and corticosterone (HBC complex, Sigma-Aldrich) $2.5 \mu \mathrm{g} / \mathrm{kg}$ dissolved in $10 \mu \mathrm{L}$ ethanol were inserted and injected respectively in a piece of apple $\left(5 \mathrm{~mm}^{3}\right)$ provided to the rats in order to avoid periodic handling or stressful signals. The apple piece (with or without hormones) was always given at the same geographical time (8:00h or ZT0). Plasma corticosterone and melatonin levels were evaluated at ZT1 and ZT12 for corticosterone and ZT1, ZT6 and ZT12 for melatonin according to the expected maximum plasma concentration $\left(T_{\max }\right)$ (Pan et al. 2006, Karatsoreos et al. 2010, Romo-Nava et al. 2014). The apple piece injected with the same amount of ethanol used to dissolve the corticosterone was used as the control treatment.

\section{Oil-red-O (ORO) staining}

Small pieces of liver tissue were fixed, cryopreserved and stained with Oil-Red-O as reported previously for representative HS images (Salgado-Delgado et al. 2013).

\section{Liver triglyceride content}

Total hepatic lipid content was extracted according to the Folch method (Folch 1957) and stored in saline-Tritón $\times 100$ solution $(1: 9)$ at $-20^{\circ} \mathrm{C}$. TG content was assessed using a TG determination kit (ELItech Clinical Systems, Paris, France).

\section{Hepatic bile acids content}

Total hepatic bile acids were determined as described by the manufacturer determination kit (Diazyme Laboratories, Poway, CA, USA). Briefly, $1 \mathrm{~g}$ of hepatic tissue was homogenized in PBS and centrifuged $10,000 \boldsymbol{g}$ for $10 \mathrm{~min}$ and supernatant was recovered and stored at $-80^{\circ} \mathrm{C}$ until used. Bile acids concentration was calculated as molar concentration per gram of tissue.

\section{Serum determinations}

Triglyceride (ELITech Clinical Systems), $\beta$-hydroxybutyrate (Sigma-Aldrich), insulin (ALPCO Diagnostics, Salem, $\mathrm{NH}$, USA), melatonin (IBL International, Hamburg, Germany) and corticosterone (MP Biomedicals, Santa Ana, CA, USA) levels in serum were determined according to the procedure of the manufacturer. For hormonal determinations, the minimum detectable doses as well as the percentage coefficient of variation (a consistency parameter of each assay) were: $0.124 \mathrm{ng} / \mathrm{mL}$ and $9.95 \%$ for insulin, $0.3 \mathrm{pg} / \mathrm{mL}$ and $12.7 \%$ for melatonin and $1.5 \mathrm{ng} / \mathrm{mL}$ and $7.2 \%$ for corticosterone, respectively. Blood samples for triglycerides, $\beta$-hydroxybutyrate and insulin were obtained as described previously for glucose in GTT section. The homeostasis model of insulin resistance (HOMA-IR) as a parameter that allows to estimate the insulin sensitivity/resistance was determined as $=(($ fasting insulin $(\mathrm{ng} / \mathrm{mL})) \times($ fasting glucose $(\mathrm{mmol} / \mathrm{L}))) / 22.5$ as previously reported (Muniyappa et al. 2008).

\section{Statistical analysis}

Results are presented as mean \pm standard error of the mean (s.e.M.). One-way ANOVA and two-way ANOVA followed by Bonferroni's and Tukey post hoc test respectively and unpaired Student- $t$ test were assayed using the GraphPad Prism, version 6.0 (GraphPad Software). Statistical significance was assumed when $P<0.05$.

\section{Results}

Constant light causes arrhythmicity, metabolic disturbances and HS

In experiment 1 , after three weeks in LL, animals showed a clear loss of locomotor activity rhythm as well as loss in corticosterone and melatonin rhythms (Fig. 1). After seven weeks in LL, the metabolic parameters were established: with respect to lipid metabolism, an increase in hepatic TG content $(8.1 \pm 0.8$ vs $5.8 \pm 0.2 \mathrm{mg} / \mathrm{g}$ of tissue, $P<0.05$; Fig. 2A, Supplementary Fig. 1, see section on supplementary data given at the end of this article), in serum TG levels $(3.9 \pm 0.6$ vs $1.3 \pm 0.1 \mathrm{mmol} / \mathrm{L}, P<0.005$; Fig. $2 \mathrm{~B})$, in ketone $\beta$-HB levels $(8.8 \pm 2.0$ vs $3.5 \pm 0.4 \mathrm{mmol} / \mathrm{L}, P<0.05$; Fig. $2 \mathrm{C})$ as well as in hepatic bile acids content $(189.4 \pm 10.5$ vs $148.4 \pm 10.1 \mu \mathrm{mol} / \mathrm{L}, P<0.05$; Fig. 2D) as compared with the LD-AL control group. Also, the LL-AL group exhibited a significant increase in the epididymal $(15.5 \pm 0.9$ vs $11.2 \pm 1.0 \mathrm{mg} / 100 \mathrm{~g}$ of body mass, $P<0.05)$, retroperitoneal

Published by Bioscientifica Ltd 
A

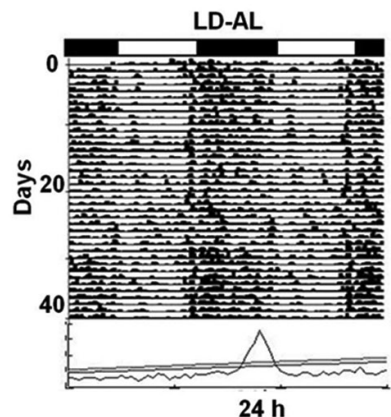

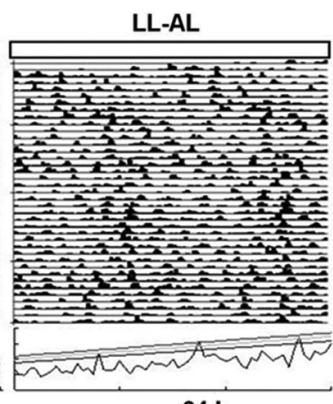

$24 h$
B

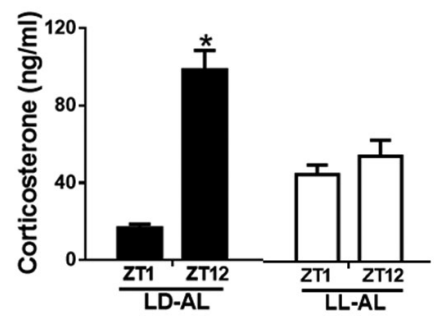

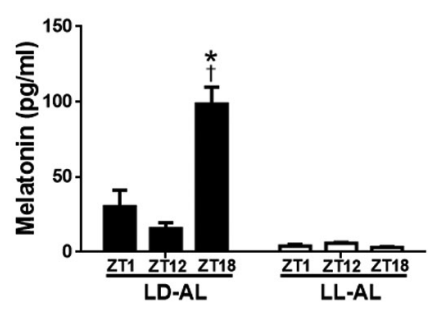

Figure 1

Constant light induces arrhythmicity in locomotor activity and hormonal levels. (A) Representative actograms that show daily locomotor activity monitored in rats under 12:12 light:darkness cycle (left) and exposed to constant light (right), both under ad libitum condition. A $\chi^{2}$ periodogram shows the absence of circadian rhythmicity under LL. (B) The levels of corticosterone and melatonin from LD ad libitum (LD-AL $=$ black bars, $n=6)$ and LL ad libitum rats (LL-AL= white bars, $n=7$ ) is shown. Data are presented as mean \pm S.E.M. *Indicates statistical difference from ZT1 in LD-AL group (Student's $t$ test; $P<0.05)$ for corticosterone levels. *Statistical difference from ZT1 and from ZT12 in LD-AL group (One-way ANOVA, Bonferroni's post hoc test; $P<0.05)$ for melatonin levels.

$(10.8 \pm 0.8$ vs $6.7 \pm 0.7 \mathrm{mg} / 100 \mathrm{~g}$ of body mass, $P<0.05)$ and subcutaneous fat pads $(16.2 \pm 0.8$ vs $9.9 \pm 0.9 \mathrm{mg} / 100 \mathrm{~g}$ of body mass, $P<0.05$ ) respectively (Fig. $2 \mathrm{E}$ ). In addition, the LL-AL group showed a considerable increase in fasting glucose $(7.4 \pm 0.8$ vs $4.7 \pm 0.2 \mathrm{mmol} / \mathrm{L}, P<0.05$; Fig. $2 \mathrm{~F}$ ) and fasting insulin level $(0.84 \pm 0.18$ vs $0.31 \pm 0.02 \mathrm{ng} / \mathrm{L}$, $P<0.05$; Fig. 2G). This result can be associated with an increased HOMA-IR ( $8.1 \pm 0.83$ vs $5.8 \pm 0.2, P<0.0001$; Fig. $2 \mathrm{H})$ as well as an impaired glucose clearance more pronounced in the LL-AL group $(P<0.0001$; Fig. 2I and $40.8 \pm 1.9$ vs $28.2 \pm 1.1$ glucose $\mathrm{mmol} / \mathrm{L} / \mathrm{min}, P<0.001$; Fig. 2J). Interestingly, body mass gain and food efficiency (Moura et al. 2012) were augmented in the LL-AL group $(\sim 40 \%, P<0.05)$, while food intake was comparable with the LD-AL group (Table 1). These results suggest that loss of circadian rhythmicity under LL seriously disturbed lipid metabolic processes and glucose homeostasis leading to HS.

\section{Rhythmic melatonin and corticosterone treatment in LL ameliorates liver steatosis and glycemia}

Since LL induces loss of circadian rhythmicity and alterations in metabolism as illustrated in experiment 1, we examined whether an induced recovery of the circadian rhythm in corticosterone and melatonin could prevent metabolic disruption of animals in LL (Fig. 3A). Hereto we
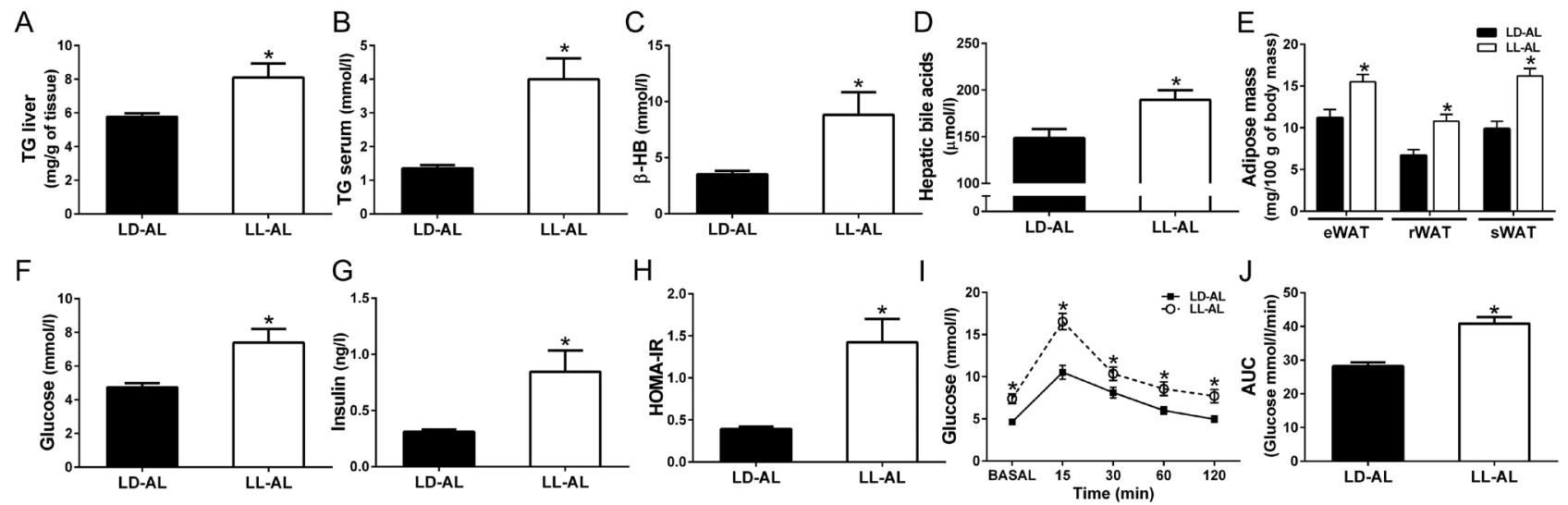

$\mathrm{J}$

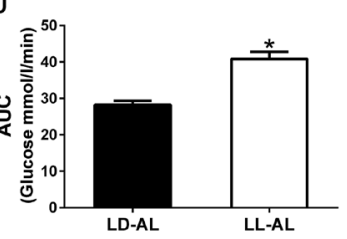

Figure 2

Metabolic disturbances caused by chronic constant light exposure. Metabolic profile of ad libitum under 12:12 LD cycle (LD-AL= black bars) and ad libitum under constant light (LL-AL=white bars) groups. (A) Hepatic TG content; (B) Serum TG; (C) $\beta$-hydroxybutyrate levels; (D) hepatic bile acids content; (E) White adipose tissue mass (eWAT = epididymal, rWAT= retroperitoneal and sWAT=subcutaneous) normalized with respect to body weight; (F) Blood glucose levels; (G) Serum insulin levels; (H) HOMA-IR (I) Glucose tolerance test (GTT) and (J) Area under the curve (AUC). Data are presented as mean \pm S.E.M. ( $n=6$ for LD-AL and $n=7$ for LL-AL). *Indicates statistical difference from LD-AL by Student- $t$ test $(P<0.05)$ and Two-way ANOVA, (only for GTT assay, Tukey's post hoc test, $P<0.05$ ) respectively. 


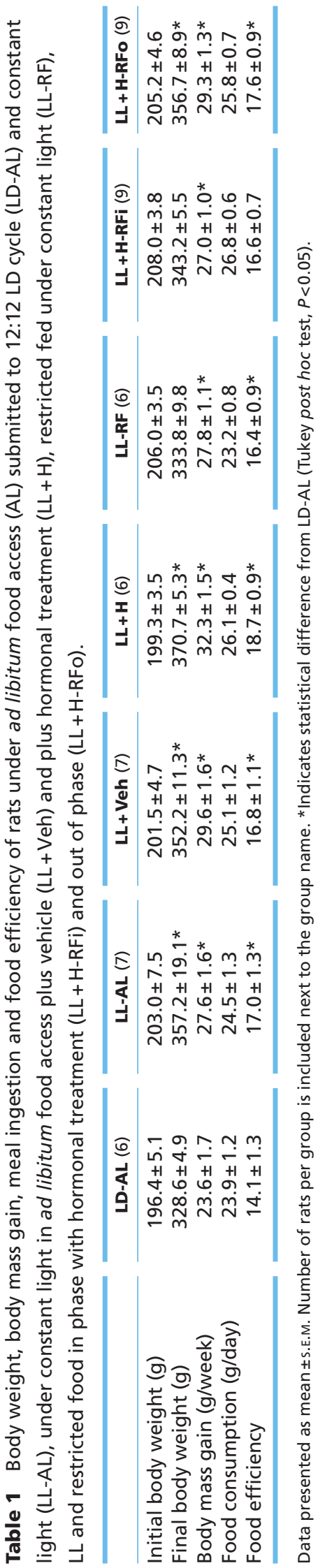

http://joe.endocrinology-journals.org DOI: 10.1530/JOE-17-0370 used a procedure whereby melatonin was provided in slowrelease capsules inserted in a piece of apple, resulting that both corticosterone (dissolved in ethanol) and melatonin could be given in the same apple piece, thus producing the normal expected pattern with high melatonin levels in the middle of the night, occurring with a difference of $6 \mathrm{~h}$ from high corticosterone levels (Fig. 1B) and Fig. 3C shows high experimental melatonin levels, $5 \mathrm{~h}$ after the corticosterone peak. This way of providing melatonin and corticosterone at the same time in the apple allowed us to mimic the 'correct' melatonin temporal signal as compared with the control group (Fig. 1B). Moreover, the apple portion used as vehicle was ingested quickly and did not provoke an entrained rhythm in arrhythmic control animals (Fig. 3B left panel); however, animals with apple-hormonal treatment recovered a rhythmic locomotor activity (Fig. 3B and C). The small piece of apple with hormones restored a 'normal' peak in both corticosterone and melatonin (Fig. 3C).

Interestingly timed corticosterone and melatonin delivery ameliorated LL induced HS about 20\% (LL+H) vs the $L L+$ Veh group $(5.8 \pm 0.7$ vs $8.7 \pm 0.7 \mathrm{mg} / \mathrm{g}$ of tissue, $P<0.01$; Fig. 4A, Supplementary Fig. 1). Also, ketone bodies and liver bile acids decreased significantly in $\mathrm{LL}+\mathrm{H}(5.0 \pm 0.6$ vs $7.1 \pm 1.2 \mathrm{mmol} / \mathrm{L}$ and $148.1 \pm 7.5$ vs $183.8 \pm 13.6 \mu \mathrm{mol} / \mathrm{L}$, $P<0.05$; Fig. $4 \mathrm{C}$ and D). However, adipose fat mass remained similar between groups (Fig. 4E). Fasting glucose level in the hormonal treated group $\mathrm{LL}+\mathrm{H}$ was significantly lower than that in the $\mathrm{LL}+$ Veh group $(5.4 \pm 0.4$ vs $7.6 \pm 0.4 \mathrm{mmol} / \mathrm{L}, \quad P<0.05$; Fig. $4 \mathrm{~F})$; yet, hormonal treated animals developed hyperinsulinemia ( $3.3 \pm 0.3$ vs $0.97 \pm 0.08 \mathrm{ng} / \mathrm{L}, P<0.005$; Fig. $4 \mathrm{G})$. In relation with this, hormonal treatment provoked an increase in HOMA-IR $(3.8 \pm 0.8$ vs $1.3 \pm 0.2, P<0.001$; Fig. $4 \mathrm{H})$ but seemed to favor an improved glucose clearance as shown by the GTT $(P<0.0001$; Fig. 4I; $30.7 \pm 2.0$ vs $40.0 \pm 1.1$ glucose mmol/L/ min, $P<0.005$; Fig. 4J) while increased body mass and food efficiency remained increased (Table 1). In addition, it is notable that numerous metabolic parameters presented by the humoral treated group were comparable to the control LD-AL group (stippled lines in Fig. 4). Therefore, daily hormonal treatment only improved HS, hyperglycemia and hyperketonemia, but did not attenuate the deleterious effects of LL such as dyslipidemia, increased body fat and body weight gain.

\section{Restricted mealtime in circadian disrupted animals ameliorated glycemia through increasing insulin levels}

Food intake acts as an important external signal that coordinates metabolism and peripheral circadian

Published by Bioscientifica Ltd. 
A

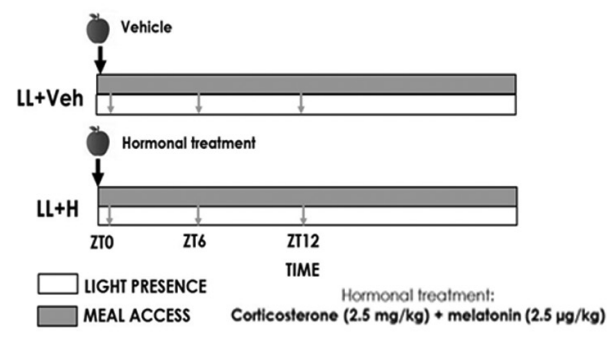

C
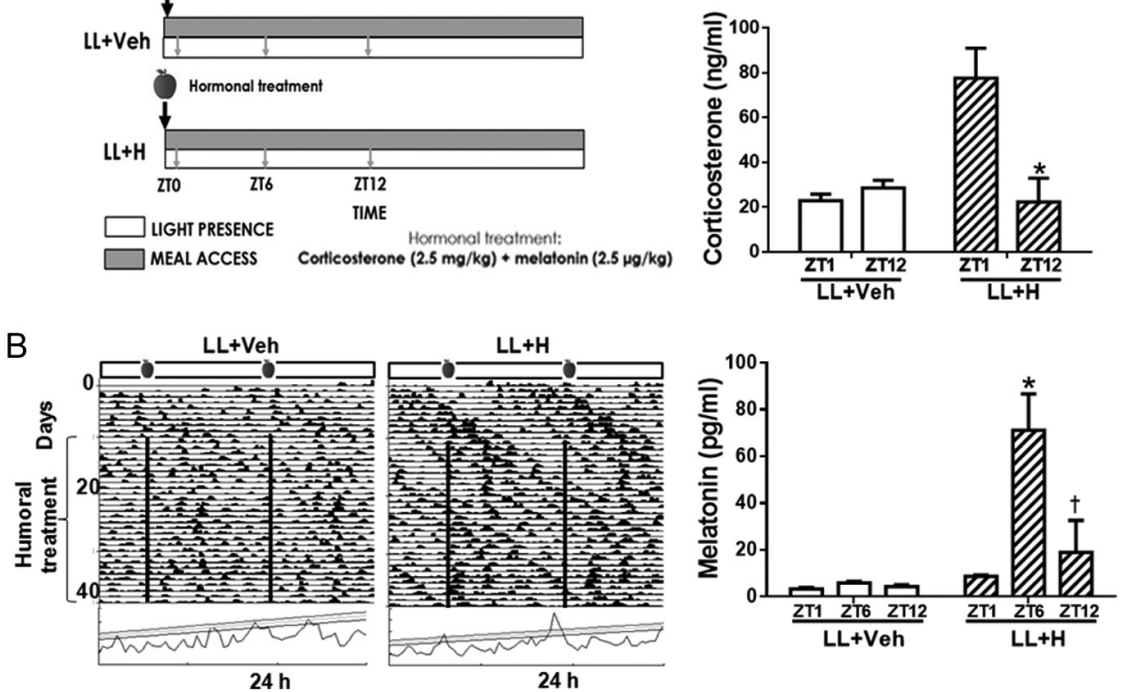

\section{Figure 3}

Hormonal treatment recovers circadian locomotor activity and humoral rhythms. (A) Experimental design for the hormonal treatment. The apples and black line represent the time of hormone administration. Gray arrows represent the time points of blood sampling for hormonal determinations. (B) The actograms of $L L+V e h$ (left) and $\mathrm{LL}+\mathrm{H}$ (right). The apples represent the time of treatment (given after three weeks of LL) and their respective $\chi^{2}$ periodogram is presented in the inferior part. (C) The levels of corticosterone and melatonin from vehicle $(\mathrm{LL}+$ Veh $=$ white bars, $n=8)$ and treated $(\mathrm{LL}+\mathrm{H}=$ dashed bars, $n=6)$ rats is shown. *Indicates statistical difference from ZT1 in LL $+\mathrm{H}$ group (Student's $t$ test; $P<0.05$ ) for corticosterone levels. *Statistical difference from ZT1 and +from ZT12 in LL-H group (One-way ANOVA, Bonferroni post hoc test; $P<0.05)$ for melatonin levels. rhythmicity. In this third experiment, we tested whether daily restricted food (LL-RF) is capable to prevent metabolic disturbances related to continuous light exposure. However, LL-RF showed an elevated hepatic TG content $(7.7 \pm 0.5$ vs $5.6 \pm 0.4 \mathrm{mg} / \mathrm{g}$ of tissue, $P<0.005$; Fig. $5 \mathrm{~A})$, serum TG $(3.9 \pm 0.2$ vs $1.3 \pm 0.1 \mathrm{mmol} / \mathrm{L}, P<0.005$; Fig. 5B) and hepatic bile acid levels $(183.6 \pm 14.1$ vs $148.4 \pm 10.0 \mu \mathrm{mol} / \mathrm{L}, P<0.005$; Fig. $5 \mathrm{D})$ as compared to LD-AL animals. Also an increase in retroperitoneal and subcutaneous adiposity was observed in LL-RF group in comparison to the LD-AL $(12.4 \pm 0.8$ vs $6.7 \pm 0.7$ and $13.7 \pm 0.9$ vs $9.9 \pm 0.9 \mathrm{mg} / 100 \mathrm{~g}$ of body mass, $P<0.005$; Fig. 5E). Serum glucose levels (Fig. 5F) and GGT test
(Fig. 5I) were comparable with LD-AL group, while hyperinsulinemia $(0.9 \pm 0.1$ vs $0.3 \pm 0.02 \mathrm{ng} / \mathrm{L}, P<0.005$; Fig. $5 \mathrm{G})$ and a higher HOMA-IR $(1.4 \pm 0.1$ vs $0.4 \pm 0.02$, $P<0.005$; Fig. 5H) persisted in the LL-RF group. Additionally, also body mass was increased in the LL-RF group $(\sim 40 \%$, Table 1$)$.

\section{Food in phase with daily hormone treatment, alleviates HS, glucose management and visceral adiposity}

As observed in experiments 2 and 3, hormonal treatment or restricted mealtime alone did not prevent all metabolic alterations caused by LL. Therefore, in the next experiment,
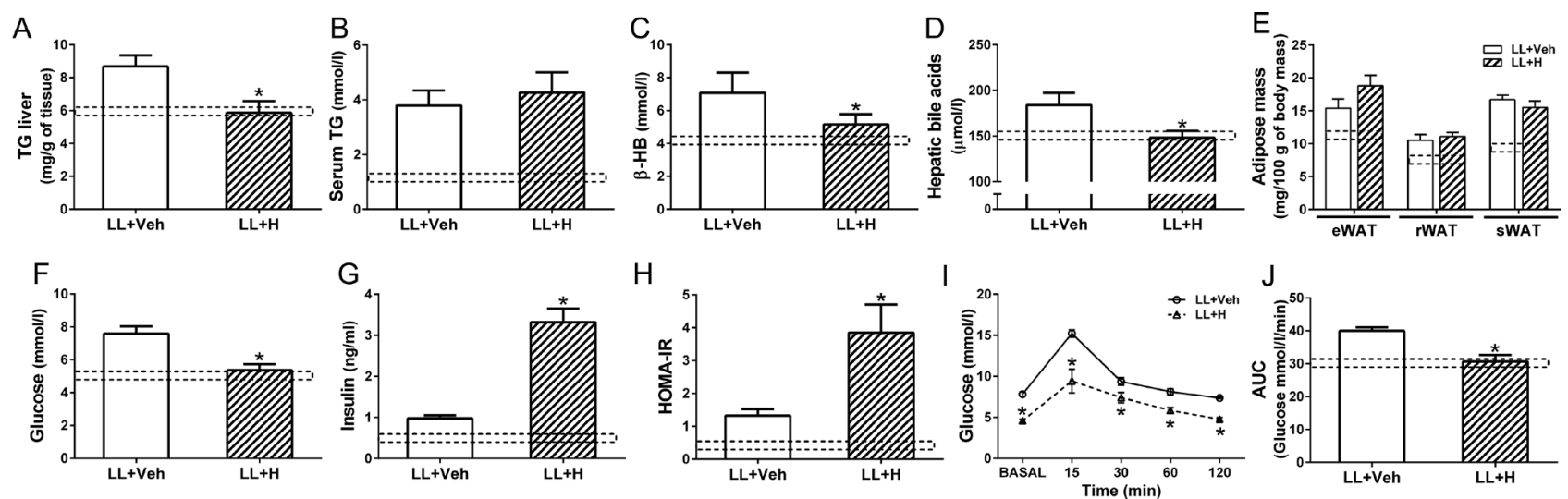

Figure 4

Hormonal treatment in LL ameliorated HS, hyperketonemia and hyperglycemia. Metabolic profile ad libitum under constant light plus vehicle ( $L L+$ Veh = white bars) and ad libitum under constant light plus hormonal treatment group (LL + H=dashed bars). (A) Hepatic TG content; (B) serum TG; (C) $\beta$-hydroxybutyrate levels; (D) hepatic bile acids content; (E) White adipose tissue mass (eWAT=epididymal, rWAT=retroperitoneal and sWAT=subcutaneous) normalized with respect to body weight; (F) Blood glucose levels; (G) Serum insulin levels; (H) HOMA-IR and (I and J) Glucose tolerance test (GTT) and the area under the curve (AUC). Data presented as mean \pm S.E.M. $(n=8 \mathrm{LL}-\mathrm{Veh}$ and $n=6 \mathrm{LL}+\mathrm{H})$. The horizontal stippled lines across histograms represent the LD-AL levels as reference. *Indicates statistical difference from LL + Veh group by Student- $t$ test $(P<0.05)$ and Two-way ANOVA (only for GTT assay, Tukey's post hoc test, $P<0.05$ ) respectively.

http://joe.endocrinology-journals.org
DOI: 10.1530/JOE-17-0370
๑ 2017 Society for Endocrinology Printed in Great Britain
Published by Bioscientifica Ltd 

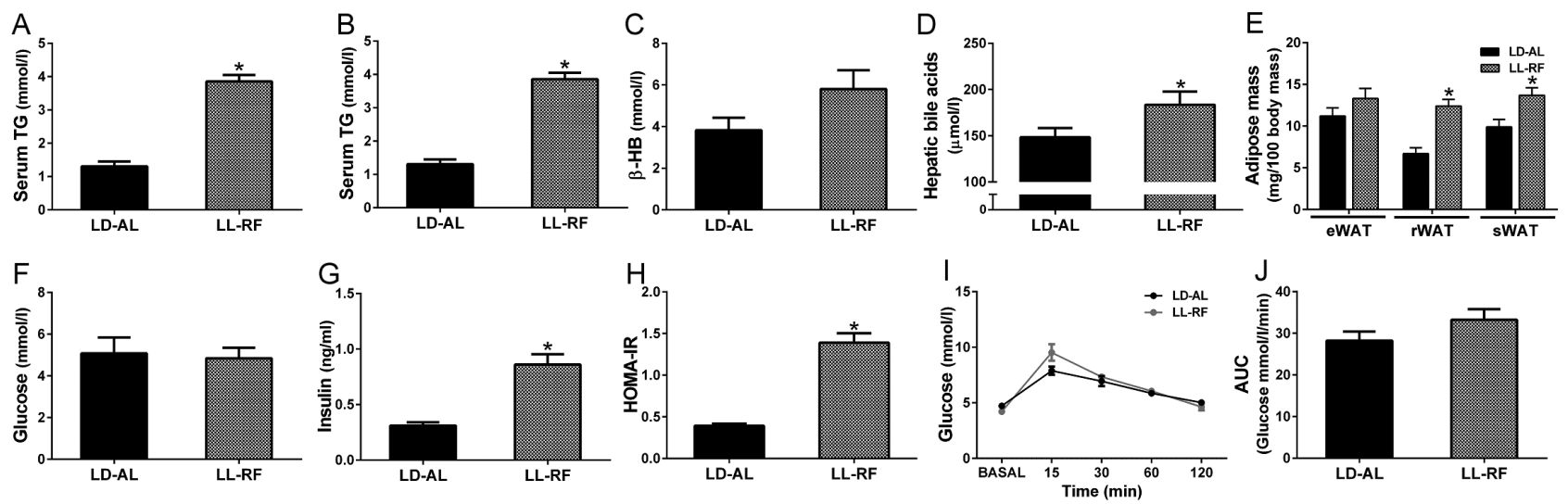

Figure $\mathbf{5}$

Scheduled restricted feeding improves glucose management homeostasis. Metabolic profile of control ad libitum fed (LD-AL $=$ black bars) under LD cycle and restricted feeding in constant light rats (LL-RF=dark gray-pointed bars). (A) Hepatic TG content; (B) Serum TG; (C) Serum $\beta$-hydroxybutyrate levels $(\beta-H B) ;(D)$ hepatic bile acids content; $(E)$ White adipose tissue mass (eWAT = epididymal, rWAT= retroperitoneal and sWAT=subcutaneous) normalized with respect to body weight; (F) Blood glucose levels; (G) Serum insulin levels; (H) HOMA-IR and (I and J) Glucose tolerance test (GTT) and its respective area under the curve (AUC). Data are presented as mean \pm s.E.M. ( $n=6$ for LD-AL and LL-RF). *Indicates statistical difference with LD-AL group (Student- $t$ test, $P<0.05)$.

we aimed to investigate the possible beneficial effect of a recovery of physiological rhythmicity by synchronizing 12-h food access with peaks of corticosterone and melatonin in phase with food $(\mathrm{LL}+\mathrm{H}-\mathrm{RFi})$, or out of phase (LL+H-RFo) with food (Fig. 6). LL+H-RFi showed comparable hepatic TG content and bile acids level as LD-AL (Fig. 7A and D). However, serum TG (3.8 \pm 0.4 vs $1.3 \pm 0.1 \mathrm{mmol} / \mathrm{L}, P<0.05$; Fig. $7 \mathrm{~B})$, ketone bodies $(9.7 \pm 0.4$ vs $3.8 \pm 0.3 \mathrm{mmol} / \mathrm{L}, P<0.05$; Fig. $5 \mathrm{C}$ ) and retroperitoneal fat pad mass $(10.8 \pm 0.8$ vs $6.7 \pm 0.7 \mathrm{mg} / 100 \mathrm{~g}$ of body mass, $P<0.05$; Fig. 7E) were increased as compared to the LD-AL group. Notably, although fasting glucose levels did not change between LL+H-RFi and LD-AL (Fig. 7F), insulin levels were increased in the $\mathrm{LL}+\mathrm{H}-\mathrm{RFi}$ group $(1.0 \pm 0.3$ vs $0.3 \pm 0.02 \mathrm{ng} / \mathrm{L}, P<0.05$; Fig. $5 \mathrm{G})$.
On the other hand, the group LL+H-RFo exhibited the worst metabolic outcome; it showed increased HS as compared to the $\mathrm{LL}+\mathrm{H}-\mathrm{RFi}$ group $(8.4 \pm 0.4 \mathrm{vs} 6.3 \pm 0.2 \mathrm{mg} / \mathrm{g}$ of tissue, $P<0.05$; Fig. 7A, Supplementary Fig. 1), marked dyslipidemia $\quad(6.0 \pm 0.4$ vs $3.8 \pm 0.4 \mathrm{mmol} / \mathrm{L}, \quad P<0.05$; Fig. 7B) and in comparison to $\mathrm{LL}+\mathrm{H}-\mathrm{RFi}$, decreased ketone bodies $(5.5 \pm 1.3$ vs $9.7 \pm 0.4 \mathrm{mmol} / \mathrm{L}, P<0.05$; Fig. $7 \mathrm{C})$. The $\mathrm{LL}+\mathrm{H}-\mathrm{RF}$ group also showed increased visceral (eWAT, $15.8 \pm 0.9$ vs $12.3 \pm 0.4 \mathrm{mg} / 100 \mathrm{~g}$ of body mass, $P<0.05)$ and increased subcutaneous adiposity $(14.6 \pm 1.2$ vs $10.7 \pm 1.1 \mathrm{mg} / 100 \mathrm{~g}$ of body mass, sWAT, $P<0.05)$ as compared to $\mathrm{LL}+\mathrm{H}-\mathrm{RFi}$ (Fig. 7E). In addition, $\mathrm{LL}+\mathrm{H}-\mathrm{RFO}$ showed severe hyperinsulinemia $(4.0 \pm 0.3 \mathrm{vs} 1.0 \pm 0.3 \mathrm{ng} / \mathrm{L}$, $P<0.05$; Fig. 7G), insulin resistance as described by HOMA-IR index $(5.9 \pm 0.5$ vs $1.6 \pm 0.5, P<0.001$; Fig. $7 \mathrm{H})$
A

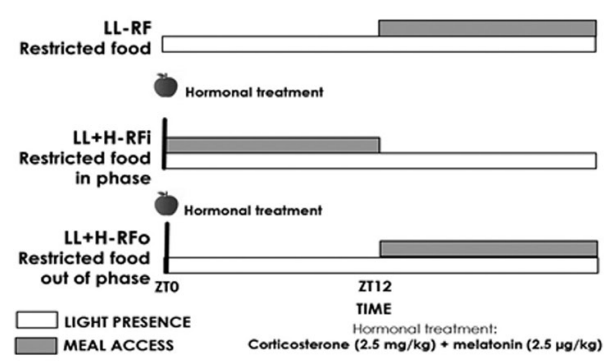

B

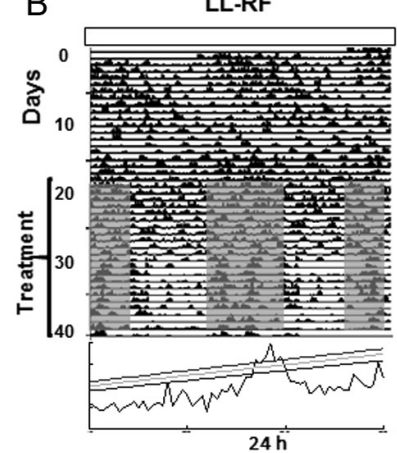

LL+H-RFi

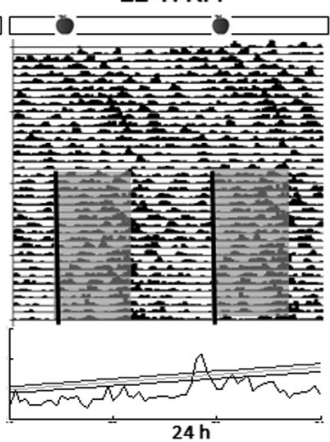

LL+H-RFo

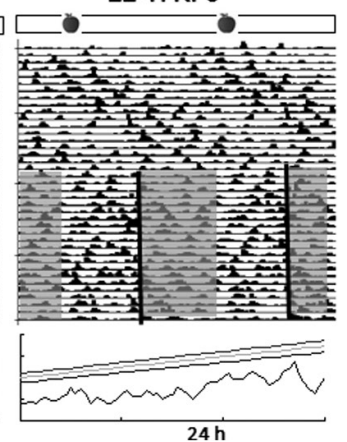

\section{Figure 6}

Food in phase with hormonal treatment is a circadian reinforcement for locomotor activity. In (A) the protocol used for hormonal treatment in animals under restricted food (LL-RF) and hormonal treatment in phase (LL+H-RFi) and out of phase (LL+H-RFo) with respect to food access. (B) represents actograms for control (LL-RF) and experimental groups ( $\mathrm{LL}+\mathrm{H}, \mathrm{LL}+\mathrm{H}-\mathrm{RFi}$ and $\mathrm{LL}+\mathrm{H}-\mathrm{RFo}$ ) respectively. Gray shadows in the actogram represent the time of meal access. Only the animals receiving hormones in phase with food show a restored rhythm.

$\begin{array}{lr}\text { http://joe.endocrinology-journals.org } & \text { ( } 2017 \text { Society for Endocrinology } \\ \text { DOI: } 10.1530 / J O E-17-0370 & \text { Printed in Great Britain }\end{array}$
Published by Bioscientifica Ltd 

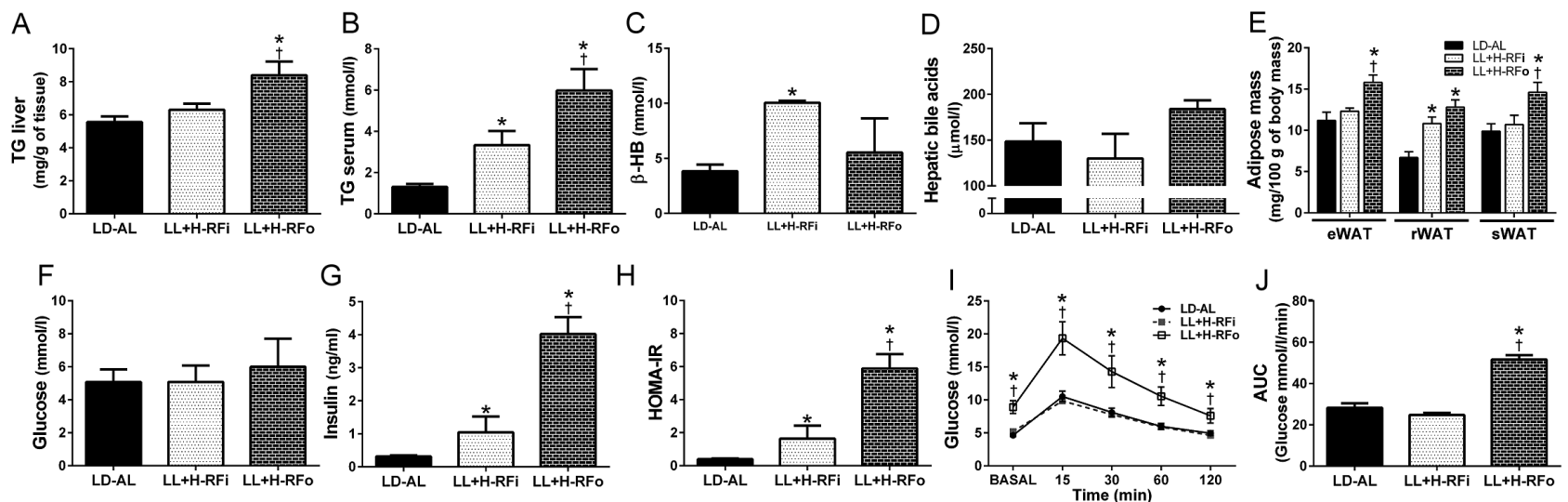

Figure 7

Hormonal treatment in phase with food improves disturbed LL glucose metabolism. Hepatic (A) and Serum TG (B), $\beta$-hydroxybutyrate levels (C), hepatic bile acids (D), white adipose tissue mass (eWAT = epididymal, rWAT= retroperitoneal and sWAT=subcutaneous) normalized with respect to body weight $(E)$, blood glucose levels (F), serum insulin levels $(G)$; HOMA-IR $(H)$ and glucose tolerance test $(I$ and J) were determined in control LD-AL (black bars $n=6)$, $\mathrm{LL}$ restricted food access in phase with hormonal treatment ( $\mathrm{LL}+\mathrm{H}-\mathrm{RFi}=$ light pointed bars) and $\mathrm{LL}$ restricted food access animals out of phase with respect to hormonal treatment ( $\mathrm{LL}+\mathrm{H}-\mathrm{RFo}=$ black pointed bar) respectively. Data presented as mean \pm s.E.M. $(n=6 \mathrm{LL}-\mathrm{RF}$ and $n=9 \mathrm{LL}+\mathrm{H}-\mathrm{RFi} / \mathrm{LL}+\mathrm{H}-\mathrm{RFo}$ ). *Indicates statistical difference against LD-AL and tfrom LL+H-RFi group by One-way ANOVA (Bonferroni's post hoc, $P<0.05$ ) and Two-way ANOVA (only for GTT assay, Tukey's post hoc test, $P<0.05)$ respectively.

and glucose clearance impairment $(P<0.001$; Fig. 7I; $51.7 \pm 3.7$ vs $24.7 \pm 1.2$ glucose $\mathrm{mmol} / \mathrm{L} / \mathrm{min}, P<0.05$; Fig. 7J) when compared with the control LD-AL and experimental LL $+\mathrm{H}-\mathrm{RFi}$ groups. Body weight gain, food consumption and meal efficiency were comparable in all experimental groups (Table 1). Consequently, mimicking corticosterone and melatonin temporal signals normally induced by the SCN in LD conditions, in synchrony with the normal food intake pattern resulted in pronounced improvement of metabolic conditions.

\section{Discussion}

The present results demonstrate that HS and metabolic disruption observed in animals maintained in LL is at least partly due to a loss of synchrony between hormonal signals driven by the SCN and food intake patterns. When animals subjected to LL received melatonin and corticosterone treatment in synchrony with food intake, HS was prevented and this treatment restored to a large extent the disturbed metabolic conditions due to LL. Therefore, our results indicate the importance of corticosterone and melatonin rhythms in synchrony with the moment of food intake.

\section{Constant light and physiological dysregulation}

Circadian desynchronization results in HS and other metabolic alterations such as dyslipidemia, hyperglycemia, insulin insensitivity and obesity, as previously reported
(Coomans et al. 2013, Salgado-Delgado et al. 2013, Aoki et al. 2014, Kim et al. 2015). Here, we show that LL in addition to the induction of locomotor and food intake arrhythmicity, also affects the daily endocrine profiles: the corticosterone circadian rhythmicity is abolished, its daytime level increased, its night time level decreased and melatonin is suppressed. This agrees with studies showing that the absence of melatonin is associated with hepatic insulin resistance and increased gluconeogenesis (Pan et al. 2006, Nogueira et al. 2011) and that increased corticosterone levels are related to increased adiposity and the development of other metabolic syndrome parameters (Woods et al. 2015). Since LL is associated with the loss of rhythmicity in various physiological and behavioral parameters, we aimed to identify which of the SCN outputs could be crucial for maintaining metabolic health.

\section{Ectopic fat accumulation is prevented by circadian hormone treatment}

In the present study, the significant body weight gain observed in LL-circadian-disrupted groups could not be explained by augmented food ingestion. Other studies have suggested that this is due to an increased metabolic efficiency, low energy expenditure and reduced locomotion (Borniger et al. 2013, Coomans et al. 2013). Many studies, including ours, report a strong correlation between visceral fat mass and hepatic lipid accumulation (Polidarová et al. 2011, Konrad et al. 2014). 
Yet, here we observed that although $\mathrm{LL}+\mathrm{H}$ showed an augmented visceral adiposity, the hormonal treatment attenuated liver steatosis. This can be explained as a result of the crosstalk between adipose-liver and proinflammatory signals that mediate fat accumulation. In obese conditions, adipose tissue inflammation may occur preventing adipose tissue to expand further, leading to fat accumulation in ectopic tissues such as the liver (Nov et al. 2013). Since corticosterone and melatonin may act as anti-inflammatory signals; these hormones may have prevented the inflammatory component in adipose tissue thus preventing hepatic fatty acid accumulation.

There is growing evidence of the participation of bile acids in the development of HS: increased levels of bile acids in the liver may induce a cascade of events driving the progression of HS through an alteration in the lipogenic pathways and a consequent lipid accumulation (Porez et al. 2012). Here, we show that circadian disruption also increased hepatic bile acid content, which recently was associated to cholestasis and peripheral clock alterations (Kettner et al. 2016). Interestingly, all humoral treated groups ( $\mathrm{LL}+\mathrm{H}, \quad \mathrm{LL}+\mathrm{H}-\mathrm{RFi}$ and $\mathrm{LL}+\mathrm{H}-\mathrm{RFo}$ ) exhibited diminished bile acid levels, indeed preventing the cholestasic profile (or diminishing HS) that was observed in circadian disrupted groups LL-AL, LL-Veh and LL-RF, respectively. This observation indicates an important role of corticosterone and melatonin rhythms on liver bile acid metabolism (Kettner et al. 2016), while food temporal signals alone did not have effect to prevent this process.

\section{Food in phase with SCN-related hormone signals improves metabolic disturbances}

The present study shows that the reinstatement of a rhythm in melatonin and corticosterone, especially when synchronized with food, improved metabolic perturbations derived from circadian disruption. Interestingly, in spite of the fact that feeding time is recognized as an important synchronizer for peripheral clock gene expression (Damiola et al. 2000), the 12-h food intake schedule could not recover the metabolic changes caused by circadian disruption. The present study shows that signals induced by scheduled food fail to a large extent to reinstate the normal liver metabolism and that in addition to food-related signals, the hormonal signals driven by the $\mathrm{SCN}$ are needed to restore for a large part the normal metabolic profile of the liver.

Of all experimental groups, only those treated with the hormones out of phase with the scheduled restricted feeding did not show improved glucose tolerance. A possible explanation is that although exogenous melatonin is associated with improved glucose homeostasis, its action mechanisms may be related to the synchrony with food intake, while also the corticosterone treatment out of phase will have increased the corticosterone levels at a non-physiological moment.

It may be argued that our results in rats may not equate with results in humans due to the time-related differences in hormone levels; the corticosterone peak several hours prior to the melatonin peak in nocturnal rodents, while the melatonin peak is several hours prior to the corticosterone peak in humans - causing a different temporal relationship between the two peaks. On the other hand, melatonin shows virtually the same daily profile independently of nocturnality or diurnality. In addition, melatonin has an important feedback role on the SCN where its receptors are expressed both in nocturnal and diurnal species (see for review Pevet 2016). Consequently the normal action of melatonin in contrast to the other hormones is always associated with the dark phase, indicating that it is either involved in supporting functions associated with sleep (in diurnal animals) or with activity (nocturnal animals) (Pevet 2016). The opposite temporal patterns in activity between diurnal and nocturnal animals has as consequence that also the circadian pattern of glucocorticoids and glucose exhibit opposite phases between diurnal and nocturnal organisms. Therefore, our present results demonstrate that not just food, melatonin or corticosterone are important but that the timing of the corticosterone and melatonin peak in relation to meal intake is crucial for the development or prevention of metabolic diseases.

\section{Conclusions}

Our results demonstrate that without synchrony between food intake and endocrine signals, normally driven by the SCN, metabolic alterations occur leading to HS. Nevertheless, in spite of amelioration of metabolic conditions by food intake in synchrony with melatonin and corticosterone rhythm, constant light still maintained a disruptive influence indicating yet additional factors influencing the metabolic condition. We propose that other SCN communication pathways in addition to food intake, corticosterone and melatonin, such as a direct autonomic nervous system influence to the liver may also participate in the aberrant SCN output due to LL.

Finally, modern life seems be associated frequently with a desynchronized life style, with all its consequences

Published by Bioscientifica Ltd. 
such as metabolic disorders. When searching for the treatment of these metabolic disturbances, very often only attention is paid to isolated elements; desynchronized food intake, sleep disruption, hormonal disruption etc. The present study shows that when only one factor is treated, the results may be small. We propose as reason: a desynchronized life style disrupts the SCN, which consequently not only results in the disturbance of one circadian parameter but also results in the disruption of many. The present study shows that all of these need attention and in the right physiological time.

\section{Supplementary data}

This is linked to the online version of the paper at http://dx.doi.org/10.1530/ JOE-17-0370.

\section{Declaration of interest}

The authors declare that there is no conflict of interest that could be perceived as prejudicing the impartiality of the research reported.

\section{Funding}

This work was supported by grants DGAPA IG-200417; CONACYT 220598. $A B R$ is a postdoctoral fellow supported by DGAPA program from UNAM (2013-2015) and CONACYT Programa de apoyo al posgrado, Posgrado de Ciencias Biomèdicas Básicas (2015-2017).

\section{Author contribution statement}

$A B R$ designed and conducted the experiments, analyzed data and wrote the manuscript. N N G V, F C M, E S, M C B conducted experiments. N N G V, F C M, E S, M C B, C E, R S D analyzed data and reviewed and edited the manuscript. R M B conceived the project, designed the experiments, analyzed data, and wrote the manuscript. R M B is the guarantor of this work and, as such, had full access to all the data in the study and takes responsibility for the integrity of the data and the accuracy of the data analysis.

\section{Acknowledgments}

The authors thank to Dr Francisco Romo (University of Cincinnati) for his kind contribution of Chronocaps capsules (melatonin) as well to Dr Luis León (Biomedical Research Institute, UNAM) for his invaluable help in the corticosterone level determination and to Dra. Mara Guzmán (Faculty of Medicine, UNAM) for her assistance in the GTT assay.

\section{References}

Adamovich Y, Rousso-Noori L, Zwighaft Z, Neufeld-Cohen A, Golik M, Kraut-Cohen J, Wang M, Han X \& Asher G 2014 Circadian clocks and feeding time regulate the oscillations and levels of hepatic triglycerides. Cell Metabolism 19 319-330. (doi:10.1016/j. cmet.2013.12.016)

Aoki N, Yoshida D, Ishikawa R, Ando M, Nakamura K, Tahara Y \& Shibata S 2014 A single daily meal at the beginning of the active or inactive period inhibits food deprivation-induced fatty liver in mice. Nutrition Research 34 613-622. (doi:10.1016/j.nutres.2014.06.004)

Ashley JP, Wright DC \& Michael CR 2011 The effects of glucocorticoids on adipose tissue lipid metabolism. Metabolism Clinical and Experimental 60 1500-1510. (doi:10.1016/j.metabol.2011.06.012)

Balsalobre A, Brown SA, Marcacci L, Tronche F, Kellendonk C, Reichardt HM, Schutz G \& Schibler U 2000 Resetting of circadian time in peripheral tissues by glucocorticoids signaling. Science $\mathbf{2 8 9}$ 2344-2347. (doi:10.1126/science.289.5488.2344)

Bedrosian TA, Fonken LK \& Nelson RJ 2016 Endocrine effects of circadian disruption. Annual Reviews in Physiology 78 109-131. (doi:10.1146/ annurev-physiol-021115-105102)

Borniger JC, Weil ZM, Zhang N \& Nelson RJ 2013 Dim light at night does not disrupt timing or quality of sleep in mice. Chronobiology International 30 1016-1023. (doi:10.3109/07420528.2013.803196)

Buijs R, Salgado R, Sabath E \& Escobar C 2013 Peripheral circadian oscillators : time and food. Progress in Molecular Biology and Translational Science 119 83-103. (doi:10.1016/B978-0-12-3969712.00004-X)

Chimin P, Farias TS, Torres-Leal FL, Bolsoni-Lopes A, Campaña AB, Andreotti S \& Lima FB 2014 Chronic glucocorticoid treatment enhances lipogenic activity in visceral adipocytes of male Wistar rats. Acta Physiologica 211 409-420. (doi:10.1111/apha.12226)

Cipolla-Neto J, Amaral FG, Afeche SC, Tan DX \& Reiter RJ 2014 Melatonin energy metabolism and obesity: a review. Journal of Pineal Research 56 371-381. (doi:10.1111/jpi.12137)

Coomans CP, van den Berg SAA, Houben T, van Klinken JB, van den Berg R, Pronk ACM, Kavekers LM, Romijn JA, van Dijk KW, Biermasz NR, et al. 2013 Detrimental effects of constant light exposure and high-fat diet on circadian energy metabolism and insulin sensitivity. FASEB Journal 27 1721-1732. (doi:10.1096/fj.12-210898)

Cruz A, Padillo FJ, Granados J, Túnez I, Muñoz MC, Briceño J, Pera-Madrazo C \& Montilla P 2003 Effect of melatonin on cholestatic oxidative stress under constant light exposure. Cell Biochemistry and Function 21 377-380. (doi:10.1002/cbf.1046)

Dallman MF, la Fleur SE, Pecoraro NC, Gomez F, Houshyar H \& Akana SF 2004. Minireview: glucocorticoids-food intake, abdominal obesity, and wealthy nations in 2004. Endocrinology 145 2633-2638. (doi:10.1210/en.2004-0037)

Damiola F, Le Minh N, Preitner N, Kornmann B, Fleury-Olela F \& Schibler U 2000 Restricted feeding uncouples circadian oscillators in peripheral tissues from the central pacemaker in the suprachiasmatic nucleus. Genes \& Development 14 2950-2961. (doi:10.1101/ gad.183500)

Dibner C, Schibler U \& Albrecht U 2010 The mammalian circadian timing system: organization and coordination of central and peripheral clocks. Annual Reviews in Physiology 72 517-549. (doi:10.1146/annurev-physiol-021909-135821)

Folch J, Lees M \& Sloane GH 1957 A simple method for the isolation and purification of total lipids from animal tissue. Journal of Biological Chemistry 226 497-509. (doi:10.1016/j.jsbmb.2015.07.020)

Goel N, Stunkard AJ, Rogers NL, van Dongen HP, Allison KC, O'Reardon JP, Ahima RS, Cummings DE, Heo M \& Dinges DF 2009 Circadian rhythm profiles in women with night eating syndrome. Journal of Biological Rhythms 24 85-94. (doi:10.1177/0748730408328914)

Gooley JJ \& Chua EC-P 2014 Diurnal regulation of lipid metabolism and applications of circadian lipidomics. Journal of Genetics and Genomics 41 231-250. (doi:10.1016/j.jgg.2014.04.001)

Hatzis G, Ziakas P, Kavantzas N, Triantafyllou A, Sigalas P, Andreadou I, Ioannidis K, Chatzis S, Stamatios F, Konstantinos P, et al. 2013 Melatonin attenuates high fat diet-induced fatty liver disease in rats. World Journal of Hepatology 5 160-169. (doi:10.4254/wjh.v5.i4.160)

Published by Bioscientifica Ltd. 
Kalsbeek A, Palm IF, La Fleur SE, Scheer FAJL, Perreau-Lenz S, Ruiter M, Kreier F, Cailotto C \& Buijs RM 2006 SCN outputs and the hypothalamic balance of life. Journal of Biological Rhythms $\mathbf{2 1}$ 458-469. (doi:10.1177/0748730406293854)

Karatsoreos IN, Bhagat SM, Bowles NP, Weil ZM, Pfaff DW \& Mcewen BS 2010 Endocrine and physiological changes in response to chronic corticosterone: a potential model of the metabolic syndrome in mouse. Endocrinology 151 2117-2127. (doi:10.1210/en.2009-1436)

Kettner NM, Voicu H, Finegold MJ, Coarfa C, Sreekumar A, Putluri N, Katchy CA, Lee C, Moore DD \& Fu L 2016 Circadian homeostasis of liver metabolism suppresses hepatocarcinogénesis. Cancer Cell $\mathbf{3 0}$ 1-16. (doi:10.1016/j.ccell.2016.10.007)

Kim TW, Jeong J \& Hong S 2015 The impact of sleep and circadian disturbance on hormones and metabolism. International Journal of Endocrinology 2015 1-9. (doi:10.1155/2015/591729)

Konrad D \& Wueest S 2014 The gut-adipose-liver axis in the metabolic syndrome. Physiology 29 304-313. (doi:10.1152/physiol.00014.2014)

Le Martelot G, Claudel T, Gatfield D, Schaad O, Kornmann B, Lo Sasso G, Moschetta A \& Schibler U 2009 REV-ERBalpha participates in circadian SREBP signaling and bile acid homeostasis. PloS Biology 7 e1000181. (doi:10.1371/journal.pbio.1000181)

Le Minh N, Damiola F, Tronche F, Schûtz G \& Schibler U 2001 Glucocorticoid hormones inhibit food-induced phase-shifting of peripheral circadian oscillators. EMBO Journal 20 7128-7136. (doi:10.1093/emboj/20.24.7128)

Ma K, Xiao R, Tseng HT, Shan L, Fu L \& Moore DD 2009 Circadian dysregulation disrupts bile acid homeostasis. PLOS ONE 4 e6843. (doi:10.1371/journal.pone.0006843)

Moura LP, Figueredo GA, Bertolini NO, Ceccato M, Pereira JR, Sponton ACS \& de Mello MA 2012 Dietary restriction, caloric value and the accumulation of hepatic fat. Lipids in Health and Disease 112. (doi:10.1186/1476-511X-11-2)

Muniyappa R, Lee S, Chen H \& Quon MJ 2008 Current approaches for assessing insulin sensitivity and resistance in vivo: advantages, limitations, and appropriate usage. American Journal of Physiology: Endocrinology and Metabolism 294 E15-E26. (doi:10.1152/ ajpendo.00645.2007)

Mustonen AM, Nieminen P \& Hyvärinen H 2002 Effects of continuous light and melatonin treatment on energy metabolism of the rat. Journal of Endocrinology Investigation 25 716-723. (doi:10.1007/BF03345106)

Nogueira TC, Lellis-santos C, Jesus DS, Taneda M, Rodrigues SC, Amaral FG, Lopes AM, Cipolla-Neto J, Bordin S \& Anhé GF 2011 Absence of melatonin induces night-time hepatic insulin resistance and increased gluconeogenesis due to stimulation of nocturnal unfolded protein response. Endocrinology 152 1-11. (doi:10.1210/en.2010-1158)

Nov O, Shapiro H, Ovadia H, Tarnovscki T, Dvir I, Shemesh E, Kovsan J, Shelef I, Carmi Y, Voronov E, et al. 2013 Interleukin-1 $\beta$ regulates fat-liver crosstalk in obesity by auto-paracrine modulation of adipose tissue inflammation and expandability. PLoS ONE 8 e53626. (doi:10.1371/journal.pone.0053626)

Owino S, Contreras-Alcantara S, Baba K \& Tosini G 2016 Melatonin signaling controls the daily rhythm in blood glucose levels independent of peripheral clocks. PLOS ONE 11 e0148214. (doi:10.1371/journal.pone.0148214)
Pan M, Song Y-L, Xu J-M \& Gan H-Z 2006 Melatonin ameliorates nonalcoholic fatty liver induced by high-fat diet in rats. Journal of Pineal Research 41 79-84. (doi:10.1111/j.1600-079X.2006.00346.x)

Pevet P 2016 Melatonin receptors as therapeutic targets in the suprachiasmatic nucleus. Expert Opinion on Therapeutic Targets 20 1209-1218. (doi:10.1080/14728222.2016.1179284)

Polidarová L, Sládek M, Soták M, Pácha J \& Sumová A 2011 Hepatic, duodenal, and colonic circadian clocks differ in their persistence under conditions of constant light and in their entrainment by restricted feeding. Chronobiology International 28 204-215. (doi:10.310 9/07420528.2010.548615)

Polidarová L, Houdek P, Sládek M, Novosadová Z, Pácha J \& Sumová A 2016 Mechanisms of hormonal regulation of the peripheral circadian clock in the colon. Chronobiology International 34 1-16. (doi:10.1194/ jlr.R024794)

Porez G, Prawitt J, Gross B \& Staels B 2012 Bile acid receptors as targets for the treatment of dyslipidemia and cardiovascular disease Journal of Lipid Research 53 1723-1737. (doi:10.1194/jlr.R024794)

Prasai MJ, Pernicova I, Grant PJ \& Scott EM 2014 An endocrinologist's guide to the clock. Journal of Clinical Endocrinology and Metabolism 96 913-922. (doi:10.1210/jc.2010-2449)

Prunet-Marcassus B, Desbazeille M, Bros A, Louche K, Delagrange P, Renard P, Casteilla L \& Pénicaud L 2003 Melatonin reduces body weight gain in Sprague Dawley rats with diet-induced obesity. Endocrinology 144 5347-5352. (doi:10.1210/en.2003-0693)

Romo-Nava F, Alvarez-Icaza González D, Fresán-Orellana A, Saracco Alvarez R, Becerra-Palars C, Moreno J, Ontiveros-Uribe MP, Berlanga C, Heinze G \& Buijs RM 2014 Melatonin attenuates antipsychotic metabolic effects: an eight-week randomized, doubleblind, parallel-group, placebo-controlled clinical trial. Bipolar Disorders 16 410-421. (doi:10.1111/bdi.12196)

Rose AJ \& Herzig S 2013 Metabolic control through glucocorticoid hormones: an update. Molecular and Cellular Endocrinology 380 65-78. (doi:10.1016/j.mce.2013.03.007)

Salgado-Delgado RC, Basualdo C, Guerrero NN, Saderi N, Escobar C \& Buijs RM 2013 Shift work or food intake during the rest phase promotes metabolic disruption and desynchrony of liver genes in male rats. PLoS ONE 8 e60052. (doi:10.1371/journal.pone.0060052)

Shimba S, Ogawa T, Hitosugi S, Ichihashi Y, Nakadaira Y, Kobayashi M, Tezuka M, Kosuge Y, Ishige K, Ito Y, et al. 2011 Deficient of a clock gene, brain and muscle Arnt-like protein-1 (BMAL1), induces dyslipidemia and ectopic fat formation. PLOS ONE 6 e25231. (doi:10.1371/journal.pone.0025231)

Suresh KP 2011 An overview of randomization techniques: an unbiased assessment of outcome in clinical research. Journal of Human Reproductive Science 1 8-11. (doi:10.4103/0974-1208.82352)

Woods CP, Hazlehurst JM \& Tomlinson JV 2015 Glucocorticoids and non-alcoholic fatty liver disease. Journal of Steroid Biochemistry and Molecular Biology 154 94-103. (doi:10.1016/j.jsbmb.2015.07.020)

Wu T, Jiang J, Yang L, Li H, Wanjing Z, Chen Y, Zhao B, Kong B, Lu P, Zhao Z, et al. 2016 Timing of glucocorticoid administration determines severity of lipid metabolism and behavioral effects in rats. Chronobiology International 34 78-92. (doi:10.1080/07420528.2016. 1238831)

Received in final form 12 August 2017

Accepted 29 August 2017

Accepted preprint published online 29 August 2017 http://joe.endocrinology-journals.org

DOI: 10.1530/JOE-17-0370
๑) 2017 Society for Endocrinology Printed in Great Britain
Published by Bioscientifica Ltd. 